\title{
Correction to: Systemic Design Engineering
}

\section{Curriculum and Instructional Results}

Jon Wade, Steven Hoffenson, and Hortense Gerardo

\section{Correction to:}

Chapter "Systemic Design Engineering"

in: E. Bonjour et al. (Eds.):

Complex Systems Design \& Management, https://doi.org/10.1007/978-3-030-04209-7_16

In the original version of the book, the spell error in third author name "Hortense Gerado" should be corrected as "Hortense Gerardo" in chapter "Systemic Design Engineering". The correction chapter and the book have been updated with the change. 